\title{
RANKING ABSORPTION PRACTICES OF KNOWLEDGE FOR COLLABORATIVE INNOVATION: WHICH IS THE IDEAL MULTI CRITERIA DECISION METHOD
}

\author{
Gendreau, Elizabeth (1); Benhayou-Sadafiyine, Lamiae (2); Le Dain, Marie-Anne (3); Summers, \\ Joshua (1) \\ 1: Clemson University; 2: Universite Internationale de Rabat; 3: Grenoble Institute of Technology
}

\begin{abstract}
This paper focuses on evolving an absorptive capacity (ACAP) assessment tool designed to help firms understand their ACAP maturity in processing external knowledge. ACAP maturity is evaluated based on a firm's capacity and willingness to do relevant ACAP practices. Although an earlier version of the ACAP tool was able to evaluate maturity and highlight immature practice, it could not determine how critical these practices were for improvement action. Thus, a means of eliciting the importance of practices and aggregating it with their ACAP maturity evaluations is needed. This paper provides summaries of the subjective weight elicitation methods and aggregation techniques which were identified from the domain of multi-criteria decision making. Criteria for comparing these methods are defined and analyzed to determine the most appropriate methods for the current application. The SRF method for subjective weight elicitation, aggregated with the maturity evaluations through weight sum models, is deemed the most appropriate for the current application. During testing with users, the SRF procedure was found to suffer from various usability concerns which will be investigated in future work.
\end{abstract}

Keywords: Collaborative innovation network, Asorptive capacity, Innovation, Decision making, Collaborative design

Contact:

Summers, Joshua

Clemson University

Mechanical Engineering

United States of America

jsummer@clemson.edu

Cite this article: Gendreau, E., Benhayou-Sadafiyine, L., Le Dain, M.-A., Summers, J. (2019) 'Ranking Absorption Practices of Knowledge for Collaborative Innovation: Which is the Ideal Multi Criteria Decision Method', in Proceedings of the 22nd International Conference on Engineering Design (ICED19), Delft, The Netherlands, 5-8 August 2019. DOI:10.1017/dsi.2019.240 


\section{MOTIVATION AND PROPOSED APPLICATION}

To stay competitive in an increasingly dynamic market, firms and their collaborators must continuously innovate by making calculated risks. These risks occur every time an investment is made in future innovation which has uncertain levels of profitability. Firms try to mitigate this risk of uncertainty by implementing what are known as innovation strategies (Baldwin and Gorecki, 1998). One such strategy is for firms (or actors) to band together to create a Collaborative Innovation Network (CIN). The goal of a CIN is to further their competitiveness as a group by sharing complementary knowledge with other actors within their network to achieve common goals (Blomqvist and Levy, 2006). As a result, CINs must make decisions concerning their innovation strategies at both the individual actor level as well as at the network level.

This motivates the development of decision aid tools which help actors and their networks identify strengths and weaknesses in their handling of external knowledge critical to innovation potential. External knowledge refers to the knowledge outside of individual firms, including the unshared expertise of other firms, as well as the expertise outside of the network. The ability of a firm to process this external knowledge is known as their absorptive capacity (ACAP) (Todorova and Durisin, 2016; Zahra and George, 2002).

In previous research, a subjective evaluation tool was developed to evaluate the ACAP maturity of firms within a CIN based on a list of practices organized within an ACAP framework (Benhayoun, Dominguez-Péry et al., 2017a; Benhayoun, Le Dain et al., 2017b). This framework groups practices into 9 groups based on which project phase the practice occurs (preparation, achievement, or one-way learning phase) as well as which of three ACAP dimensions they pertain to (acquisition, assimilation, or application) within that project phase.

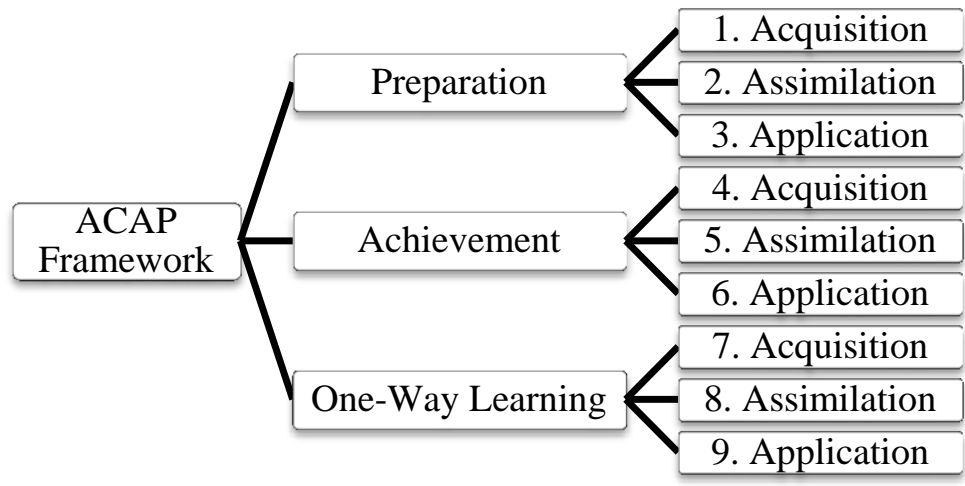

Figure 1. Nine groups of practices organized based on project phase and ACAP dimension

(Gendreau, 2017, 2018)

Using the tool, each group's practices are evaluated using two 4-point scales corresponding to the firm's (1) capacity and (2) willingness to do the practice. Based on this evaluation, the tool then outputs a grid which sorts each practice based on its maturity (Benhayoun, Dominguez-Péry et al., 2017a; Benhayoun, Le Dain et al., 2017b). The aim of this maturity grid is to highlight immature practices which the firm is less than capable of completing or is unwilling to do so that users can inform their decision making.

However, this tool has two limitations: (1) the evaluation did not consider how important highlighted practices were to the firm and (2) it was limited to evaluating firms individually and was not capable of summarizing the maturity of the entire CIN.

The importance of practices communicates the criticality of the practice to the firm, regardless of their capacity or willingness to do the practice. Thus, practices which the firm identifies as being both important but also immature should be strongly considered when deciding upon improvement actions. The importance and maturity evaluations within each group of practices can then be aggregated into numerical scores of capacity and willingness for that group. These scores highlight project phases and ACAP dimensions where more holistic improvement actions are needed. Concentrating on these critical practices, phases, and dimensions helps innovation management decision makers at a firm to focus their efforts. Further aggregating the scores of a group of firms within a CIN can then similarly be used to direct network-level decision making. 
Multi-criteria decision making (MCDM) techniques were reviewed to determine an appropriate means of eliciting subjective importance weights and aggregating them with the existing ACAP maturity evaluations. This paper will summarize and compare these methods using criteria to determine which was ideal for the current application. The final ACAP assessment tool is divided into two parts: (1) the assessment of an individual firm and (2) the assessment of the network of firms. The work included in this paper will focus on the assessment of the individual firm.

\section{REVIEW OF MCDM METHODS}

A review of MCDM literature was conducted to determine (1) an appropriate subjective importance weight elicitation method for the practices as well as (2) a method for aggregating this importance with the existing evaluations of ACAP maturity. The purpose of MCDM is to use a list of criteria to evaluate a set of alternatives (Triantaphyllou, 2000). For the present case, the practices which are used to evaluate the ACAP maturity of a firm would be the criteria being considered. The objective of the assessment would be to decide amongst a list of alternatives, in this case the project phases and ACAP dimensions, which should be the focus of the firm's improvement action decision making. As the results of the assessment are implicit rather than explicit, an improvement plan of action must be interpreted by the decision maker based on the practices, project phases, and ACAP dimensions identified by the assessment, as well as by the decision maker's own experience (Gendreau et al., 2017).

Three general approaches for eliciting subjective importance weights within MCDM are (1) ranking, (2) pairwise comparison, and (3) rating. Ranking based weight elicitation methods refer to those which require the user to put a numerical rank next to each criterion relative to other criterion which is then used to calculate the weight (Eckenrode, 2018). Pairwise comparison is believed to the most popular weight elicitation method based on the large quantity of software available which support it compared to other methods (Zardari et al., 2015). Rating methods are those methods where a weight is elicited directly from the user (Doyle et al., 1997).

\subsection{Ranking methods}

Ranking based weight elicitation methods refer to those which require the user to put a numerical rank next to each criterion (Eckenrode, 2018). The methods included in this review are Simos' method, ratio and swing weighting methods, and rank exploitation methods.

\subsubsection{Simos' method and SRF}

Simos' method refers to a weight elicitation and normalization method for multi-criteria situations which was originally proposed in 1990 by Jean Simos (Simos, 1990). The method is considered to be well adapted to users for the purposes of eliciting subjective importance weights as it is easy, simple, and fast for them to express their preferences as an ordering of criteria. The method also has the advantage of allowing criteria to share the same rank, also referred to as being "ex aequo," and does not depend upon either the range of the scale or on the encoding of criteria to express the evaluation on this scale. This is particularly useful as users tend to prefer to express their preferences spontaneously without having a set range of the scale. The process of weight elicitation remains the same for both Simos' original and revised methods with the exception of the final step. Generalized steps for Simos' methods are summarized below:

1. Criteria are ranked from most important to least important allowing for criteria to share rank as needed

2. The minimum difference between two ranks is identified and set as equal to one unit of difference in importance

3. The difference between ranks is defined in terms of this unit of difference

4. Revised Simos' (SRF) method only: a z-factor representing how many more times important the most important criterion is compared to the least important is defined by the user

To complete these steps, Simos proposes that the decision maker be presented with a set of cards each corresponding to one of the criteria being considered. These criteria cards are then grouped into same rank subsets as needed and then positioned in order of their rank of importance. The decision maker is then asked to consider the difference of importance between each rank and to define the smallest difference as 1 unit. The intervals between ranks are now all considered to have at least 1 unit of difference. The decision maker is then presented with an unlimited number of white cards each 
corresponding to 1 additional unit of difference between ranks. This means that if $\mathrm{AB}$ were the smallest interval it would have no white cards; an interval twice as large as this interval would have 1 white card. The computation of the normalized weights based on this elicitation differs slightly between the original and revised methods. In the original method, the z-factor - which is user defined in the revised method is calculated in a way which is both uncontrolled by the user as well as insufficiently founded in theory. The revised method improves upon the original method by allowing the user to control this z-factor and changing certain computing rules to strengthen its theoretical validity. This revised Simos' method is known as the Simos-Roy-Figueira (SRF) method (Figueira and Roy, 2002).

\subsubsection{Ratio weighting and swing weighting}

Ratio weighting elicitation is quite similar to Simos' original method; however this method chooses to set the least important criteria equal to 10 points as opposed to 1 unit. This encourages the user to use intermediate values to break ties however criteria of the same rank are not specifically forbidden. Despite this ability to be more precise, the decision maker is still generally encouraged not to be too analytical with their elicitation as a gross estimation is adequate.

1. Criteria are ranked from most important to least important

2. The least important is assigned a weight of 10 points

3. Every other criterion is then assigned a weight based on their ratio of importance relative to the least important criteria

4. The ratio between each criteria weight is then verified iteratively and the number of units is adjusted as needed

The importance weights are then simply normalized by dividing each criteria's weight by the sum of all weights (Edwards, 1977). This method has the advantage of being algebraic, decomposed, and direct (Zardari et al., 2015).

Alternatively is the swing weighting method (Von Winterfeldt and Edwards, 1993), shown in the following steps:

1. All criteria are assumed to have their worst evaluations and one at a time are allowed to swing to their best evaluations

2. Criteria are ranked based on their perceived level of improvement gained from this swing

3. The criterion with the most preferred swing is given 100 points

4. The magnitudes of every other swing are given as percentages of the largest swing

Similar to the ratio weighting method, these raw weights are simply normalized by dividing each weight by the sum of all (Zardari et al., 2015). This method is unique in that it uses a theoretical worst possible alternative as its reference point for comparison of criteria rather than a unit based on the criteria themselves (Edwards and Barron, 1994). It should be noted that hypothetical judgments such as those required for this method can be unreliable and unrepresentative of real preferences and can also risk causing decision makers unfamiliar with MCDM to lose confidence with the process (Edwards, 1977).

\subsubsection{Rank exploitation methods: $R S, R E, R R$, and ROC}

For situations where the decision maker cannot be relied upon, simpler methods may be ideal (Edwards, 1977). The rank sum (RS), rank exponent (RE), and rank reciprocal (RR) methods are by far the simplest weight elicitation methods. These rely upon the assumption that ranks are evenly spaced which means the decision maker does not to specify beyond the ranks themselves. However, in reality these methods should only ever be considered weight approximation techniques. The entire elicitation process is limited to the following single step:

1. Criteria are ranked from most important to least important, each criterion with its own unique rank

Such methods as these compromise on their precision and accuracy to maximize their ease of use. They are particularly useful for situations where the decision maker is unavailable, unable, or unwilling to be more precise with their weights. Unfortunately, these methods lack any real theoretical foundation and do not allow for criteria to be ranked at the same level which is clearly not reasonable in practice. The methods also become increasingly inappropriate for large numbers of criteria as it becomes more difficult to straight rank (Malczewski, 1999; Zardari et al., 2015). RS is shown in equation (1), RE in equation (2), and RR in equation (3) where $n$ refers to the number of criteria, $w_{i}$ is the normalized importance weight, and $p$ refers to an undefined value of dispersion in the weights. 


$$
\begin{aligned}
& w_{i}=\frac{n+1-i}{\sum_{j=1}^{n} j}=\frac{2(n+1-i)}{n(n+1)}, i=1, \ldots, n \\
& w_{i}=\left(\frac{n+1-i}{\sum_{j=1}^{n} j}\right)^{p}=\left(\frac{2(n+1-i)}{n(n+1)}\right)^{p}, i=1, \ldots, n \\
& w_{i}=\frac{i^{-1}}{\sum_{j=1}^{n} j^{-1}}, i=1, \ldots, n
\end{aligned}
$$

The fourth of these methods - rank order centroid (ROC) as shown in equation (4) - is similar to the RS, RE, and RR methods in that it only needs the decision maker to straight rank criteria using unique ranks.

$$
w_{i}=\frac{1}{n} \sum_{j=i}^{n} \frac{1}{j}, i=1, \ldots ., n
$$

In a simulation study where theoretical "true" weights were compared to simulated experimental values, it was found that ROC outperforms RR which outperforms RS based upon three measures of efficacy (Barron and Barrett, 1996). It is the superior of rank exploitation methods but is similarly not heavily founded in theory and should only be used to approximate importance weights.

\subsection{Pairwise comparison methods}

Pairwise comparison is believed to be the most popular weight elicitation method based on the large quantity of software available which support it compared to other methods (Zardari et al., 2015). The methods considered in this review are original Saaty's scale and the fuzzy approach.

\subsubsection{Original saaty's scale and alternative scales}

Saaty is most well-known for his development of the Analytical Hierarchy Process (AHP) which uses pairwise comparison matrices, such as the one shown in Table 1, using a fundamental scale of absolute numbers as shown in Table 2 .

Table 1. Simple three-element pairwise comparison matrix

\begin{tabular}{|r|r|r|r|}
\cline { 2 - 4 } \multicolumn{1}{c|}{} & Element 1 & Element 2 & Element 3 \\
\hline Element 1 & E1 relative to E1 & E1 relative to E2 & E1 relative to E3 \\
\hline Element 2 & E2 relative to E1 & E2 relative to E2 & E3 relative to E3 \\
\hline Element 3 & E3 relative to E1 & E3 relative to E2 & E3 relative to E3 \\
\hline
\end{tabular}

Table 2. Fundamental scale of absolute numbers (Saaty, 2008)

\begin{tabular}{|l|l|}
\hline Importance Intensity & Definition \\
\hline 1 & Equal Importance \\
\hline 2 & Weak or slight \\
\hline 3 & Moderate importance \\
\hline 4 & Moderate plus \\
\hline 5 & Strong importance \\
\hline 6 & Strong plus \\
\hline 7 & Very strong or demonstrated importance \\
\hline 9 & Very, very strong \\
\hline Reciprocals of above & $\begin{array}{l}\text { Extreme importance } \\
\text { assigned to it when compared with activity } j \text {, then } j \text { has } \\
\text { the reciprocal value when compared with } i\end{array}$ \\
\hline $1.1-1.9$ & If the activities are very close \\
\hline
\end{tabular}

To calculate the weight of an element, the sum of each row in the matrix is found and then divided by the total of these sums. This scale is normally simplified to its primary rungs 1, 3, 5, and 9 however 2, 4, 6, and 8 are introduced to distinguish between two elements of similar importance. Saaty also allows for 
decimals if an extremely small distinction in importance is desired, particularly for large numbers of criteria. The diagonal of the matrix, shown in black in Table 1, compares each element to itself and thus is automatically equal to 1 using the scale above. In a consistent matrix, the values below this diagonal, shown in grey, would merely be the inverse of the values above the diagonal. To save time, this lower half can be simply calculated based on the upper half for this reason. However, if the decision maker does complete the bottom half of the matrix their consistency can be calculated and verified. In AHP, pairwise comparison is used to determine the weights of elements at each level of a hierarchy. An additive aggregation method is then used to determine overall weights and/or scores based on this hierarchy. This process can be rather tedious for evaluations with many criteria or alternatives based on the increasingly large number of comparison that must be made (Saaty, 2008).

Some authors have challenged the original linear value scale proposed by Saaty and have developed alternative scales. Ultimately, the true distribution of priority values is never truly known, thus the goal of choosing a scale is merely to choose the most appropriate based on the nature of the preferences (Beynon, 2002). As the shape and location of the distribution of preferences is non-critical to the current application, Saaty's linear scale was deemed adequate.

\subsubsection{Fuzzy approach}

Fuzzy data sets are those which are allowed to occur over a real interval so that the data avoids having sharp boundaries (Dubois and Prade, 1980). This approach allows data to be given with fuzziness, or with a tolerance, or vagueness which is useful for situations where only estimations of data are possible (Chang and Lee, 1995). Fuzzy is in no way limited to pairwise comparison type weight elicitations, however it is most frequently published within pairwise comparison based MCDM methods (Mardani et al., 2015). Following the fuzzy approach, the same 9-point scale as shown in Table 2 is used, however the descriptions of the values between one and nine are fuzzified. For example, "moderate importance" which is normally represented as a three would become "approximately moderate importance" and would actually represent an interval about three; the extremes at one and nine, however, would remain as crisp numbers (Ho et al., n.d.). The size and shape of the interval around the fuzzy numbers is based on the type of fuzziness chosen, such as the Croquet's or Sugeno's fuzzy integrals. It is important to note that fuzzy inputs also result in fuzzy outputs and that the "grade of fuzziness" can be understood as a grade of certainty. The more fuzzy the output, the more probable, or certain, it is that the true value is contained within that interval (Dubois and Prade, 1980).

\subsection{Rating methods}

Rating methods elicit numerical weights directly from the decision maker (Doyle et al., 1997). Those which will be included here are budget point allocation, direct rating, and graphical rating.

\subsubsection{Budget (or fixed) point allocation}

Budget point allocation, sometimes referred to as fixed point allocation, forces the decision maker to give relative weights of criteria by making trade-offs between their importance weights. Following the method, the user is asked to distribute a predefined budget of points - usually 100 points as it is easiest to normalize - amongst a list of criteria. In doing so, the decision maker is only able to give a higher importance to a criterion by lowering the importance of another. This method does allow for criteria to have the same weight if the decision maker chooses. Distributing points can be a mentally difficult task for the decision maker to do directly as it is difficult to associate a numerical value to one's preferences (Zardari et al., 2015).

\subsubsection{Direct rating (likert) and graphical rating}

The direct rating technique is aptly named as the decision maker directly weights a list criterion using a Likert-like numerical scale - usually 1-5, 1-7, or 1-10 - based on strength of importance. There are no trade-offs between criteria and the user is not forced to compare criteria strengths in any way. Graphical rating is similar however instead of a numerical scale the decision maker is offered a number line with numerical values associated to it. This can be either a shared line for all criteria which encourages the user to compare criteria, or an independent line for each criterion where each is evaluated independently though the user may iteratively verify their ratios at the end. A shared line encourages the user to indicate weights somewhat relative to other criteria however it can become cumbersome when there are many criteria. Using independent lines for each criterion is much easier to do, however the user is in no way forced to 
consider relative importance of criteria. This method is often criticized for allowing the decision maker to be too carefree in their assignment of weights (Zardari et al., 2015).

\subsection{Aggregation methods}

The weighted sum model (WSM), sometimes referred to as simple additive weighting (SAW), uses the formula shown in equation (5) where $w_{i}$ refers to the relative weight of the criteria, $x_{i}$ refers to the score of criteria, and $A_{j}$ refers to the calculated aggregate score.

$$
A_{j}=\sum w_{i} x_{i j}
$$

It is important to note that $A_{j}$ normally refers to the aggregate score of an alternative which would be evaluated based on the same criteria. This approach is completely compensatory which means that its accuracy is heavily reliant upon the encoding of criteria. This method has the advantage of being very simple to implement and is widely used, in particular for AHP, for this reason despite its weakness.

Encoding of criteria refers to the nature of the scale that is used for evaluation. For example, when deciding among a list of alternative cars to purchase, the price of the car as a criterion may be extremely important to the decision. However, if the prices of all cars only range between 15,000 and 15,100 then the increase or decrease in price may not be important (Edwards and Barron, 1994). In a unidimensional problem where all criteria are measured in the same units, such as dollars, this does not pose a problem. However, if the cars are also being compared based on a criterion of a different unit - such as comfort level - the range in comfort levels between vehicles may be significant even when the criteria itself is not the priority. It therefore becomes difficult to evaluate price the same way one evaluates comfort level to create a meaningful score. It is for this reason that the weighted sum model is only truly appropriate for single dimensional problems where there are no changes in the units of evaluation among criteria (San Cristóbal Mateo, 2012).

The other method which was considered though quickly eliminated was the weighted product method (WPM) which multiplies a series of ratios for each criterion which is then raised to the power equivalent to the relative weight of that respective criterion as shown in equation (6) below where $a$ is the evaluation of a criterion, $w$ is the relative weight of that criterion, and $R\left(\frac{A_{k}}{A_{l}}\right)$ is the ratio of preference between two alternatives.

$$
R\left(\frac{A_{k}}{A_{l}}\right)=\prod_{j=1}^{n}\left(\frac{a_{k j}}{a_{l j}}\right)^{w_{j}}
$$

This method produces a list of ratios for each alternative relative to other alternatives. These ratios can then be used to create a ranked list of alternatives. If a performance value - or score - is desired, the formula can be modified as shown in equation (7) (Choo et al., 1999; San Cristóbal Mateo, 2012).

$$
P\left(A_{k}\right)=\prod_{j=1}^{n}\left(a_{k j}\right)^{w_{j}}
$$

The weighted product method differs from the additive model in that it tends to over-value the extremes. This means that criterion far from the average are considerably favoured or un-favoured within the final score. As this was not particularly relevant to the current application, the additive method was used.

\section{METHOD SELECTION AND APPLICATION}

Ranking, rating, and pairwise comparison methods for weighting criteria have been compared in the past and it has been found that there were no significant differences in the results between these methods (Eckenrode, 2018). However, each method does differ in terms of its accuracy, ease of use, complexity for users, and theoretical foundations and should be chosen specific to the problem at hand to optimize these comparison criteria (Zardari et al., 2015). Using evidence from literature, a blunt rating technique was used to evaluate how well the reviewed methods met these criteria: either high $(\mathrm{H})$, medium $(\mathrm{M})$, or low $(\mathrm{L})$ as defined in Table 3. The results of this rating, as summarized in Table 4 , were used to justify the method selected. 
Table 3. Comparison criteria for deciding appropriate importance weight elicitation method

\begin{tabular}{|l|l|}
\hline Criteria & Definition and Scale \\
\hline Accuracy & $\begin{array}{l}\text { How well the measured weights reflect the true weights, generally based on the } \\
\text { rationale of the method (Zardari } \text { et al., 2015). High means that the true and measured } \\
\text { weights are very close and low means that these weights are not. }\end{array}$ \\
\hline $\begin{array}{l}\text { Ease } \\
\text { (Speed) of } \\
\text { use }\end{array}$ & $\begin{array}{l}\text { Is often at the cost of accuracy and is based on the quickness of the method's used } \\
\text { (Zardari } \text { et al., 2015) which is critical as many decision makers do not have lots of } \\
\text { time for more complex - though maybe more accurate - approaches (Hajkowicz } \text { et al., } \\
\text { 2000). High means that the method is quick to use and low means that it is time } \\
\text { consuming. }\end{array}$ \\
\hline $\begin{array}{l}\text { Simplicity } \\
\text { for users }\end{array}$ & $\begin{array}{l}\text { An items importance is cognitively understood as informal natural language rather } \\
\text { than quantitatively (Honda } \text { et al., 2010; Mardani } \text { et al., 2015). If a method is too } \\
\text { complex, a lack of understanding of the method and resultant weights will often result } \\
\text { in the model being misused (Zhang } \text { et al., 1992). High means that the method is easy } \\
\text { to understand and low means that it is complex and prone to being misused. }\end{array}$ \\
\hline $\begin{array}{l}\text { Theoretical } \\
\text { foundation }\end{array}$ & $\begin{array}{l}\text { Attention must be given to not oversimplify the extraction; the experimental } \\
\text { calculated weight must well represent the theoretical true weight (Choo } \text { et al., 1999). } \\
\text { High means that the method is well founded in theory and low means that the method } \\
\text { is unfounded or poorly founded. }\end{array}$ \\
\hline
\end{tabular}

Table 4. Comparison of subjective weight elicitation methods from MCDM

\begin{tabular}{|c|c|c|c|c|c|}
\hline & & Accuracy & $\begin{array}{l}\text { Ease (Speed) } \\
\text { of Use }\end{array}$ & $\begin{array}{l}\text { Simplicity } \\
\text { for Users }\end{array}$ & $\begin{array}{l}\text { Theoretical } \\
\text { Foundation }\end{array}$ \\
\hline \multirow{4}{*}{$\begin{array}{l}\text { Ranking } \\
\text { Methods }\end{array}$} & Simos' Method and SRF & $\mathbf{H}$ & M & M & H \\
\hline & Ratio Weighting & M & M & M & M \\
\hline & Swing Weighting & $\mathbf{M}$ & $\mathbf{M}$ & $\mathbf{L}$ & $\mathbf{L}$ \\
\hline & Rank Exploitation & $\mathbf{L}$ & $\mathbf{H}$ & $\mathbf{H}$ & $\mathbf{L}$ \\
\hline \multirow{2}{*}{$\begin{array}{l}\text { Pairwise } \\
\text { Comparison }\end{array}$} & Saaty's Scale & $\mathbf{H}$ & $\mathbf{L}$ & $\mathbf{H}$ & M \\
\hline & Fuzzy & $\mathbf{H}$ & $\mathbf{L}$ & $\mathbf{H}$ & $\mathbf{H}$ \\
\hline \multirow{3}{*}{$\begin{array}{l}\text { Point } \\
\text { Allocation } \\
\text { and Rating }\end{array}$} & $\begin{array}{l}\text { Budget (Fixed) Point } \\
\text { Allocation }\end{array}$ & $\mathbf{M}$ & M & M & $\mathbf{L}$ \\
\hline & Direct Rating & $\mathbf{L}$ & $\mathbf{H}$ & $\mathbf{H}$ & $\mathbf{L}$ \\
\hline & Graphical Rating & $\mathbf{L}$ & $\mathbf{H}$ & $\mathbf{H}$ & $\mathbf{L}$ \\
\hline
\end{tabular}

It was decided that SRF should be used to elicit importance weights of practices within the individual firm ACAP assessment tool as it was the method most well balanced across the four criteria considered which were assumed to have approximately equal weight. As WPM had already been eliminated, the WSM was easily applied for aggregating the importance weights with the ACAP maturity evaluations.

For use with the Excel based ACAP assessment tool, the SRF procedure had to be adapted based on requirements of the problem. The two most significant of these requirements was that the tool (1) should be designed so that it can be used without a facilitator present and (2) should not use any supporting materials beyond what the software was able to provide. To accomplish this, the generalized SRF steps from 2.1.1 were automated within the programming limitations of Excel. The procedure instruction that would normally be given by a facilitator was replaced by written instructions and triggerable error messages. Instead of criteria cards being arranged on a table, the user would simply assign numerical rank values directly to the practice within the spreadsheet. The blank cards were similarly represented numerically instead of by being physically arranged.

\section{USABILITY TESTING}

Usability testing following the scripted Krug approach was then conducted to identify and fix usability concerns within the tool (Krug, 2010). All studies were conducted by the same facilitator with no additional observers present, thus the audio was recorded for post-analysis to ensure feedback was 
being thoroughly considered. Participants were asked to think-aloud during the study and would be prompted to do so by the facilitator as needed.

All five participants in the studies were industrial engineering graduate students unfamiliar with the concepts of ACAP or CINs. All participants had indicated during a brief interview at the start of the test that they had never heard of or had used the SRF method prior to being introduced to the tool during the study.

Following the script, users were first asked to navigate throughout the tool to understand its general structure. They were then asked to imagine themselves in the following scenario:

For the rest of the study, imagine that you represent an SME within a Collaborative Innovation Network (or CIN) and that your network is working together on an innovation project. In this scenario, your research project will be your innovation project, [your research lab] will be the SME that you are representing, and all other industrial partners involved in the project are other actors within your network.

You may not know exactly what Absorptive Capacity (ACAP) is, however you would like to learn how to use the concept to your advantage. You have received the auto-evaluation tool in front of you in order to do this.

It is understood that [your research lab] is not truly an SME. You may need to use your imagination during the test. Remember that the objective of this study is for us to evaluate the functionality of the tool and not on its accuracy.

After giving users an opportunity to ask questions about what was expected of them during the study, the participant was then tasked with completing the individual ACAP assessment using the tool strictly following the directions available on the tool for each task. Facilitator intervention was limited as much as possible, however intervention would be made once it became clear that the participant was unable to complete a task. At the end of the study, a brief exit interview was used to elicit any additional feedback they may have and to clarify what aspects of the tool did not reach their expectations.

Based on this testing, it was found that the adaptions made to the SRF procedure had a significant negative impact on its ease of use and simplicity. The written instructions for SRF were clarified between studies as points of confusion were identified, however the procedure remained unintuitive. No users were able to complete the tasks without at least some intervention from the facilitator. Written instructions were found to not be an adequate replacement of a facilitator given how the SRF method was adapted. These findings ultimately disqualified SRF from being a viable candidate for the Excel based ACAP assessment tool. A simpler method with greater ease of use, such as direct rating or rank exploitation, should be considered in lieu of SRF.

\section{CONCLUSIONS}

Based on four MCDM method comparison criteria identified from literature, the SRF method for eliciting importance weights was identified as a good candidate for use within the ACAP assessment tool. SRF was then adapted based on the requirements of the problem. These adaptations were later found to have had a significant negative impact on the method's ease of use and simplicity. It is therefore not recommended to apply SRF in situations where written instructions must be relied upon and a facilitator cannot be present. In these cases, the simplicity and ease of use of the method should have the greatest weight when initially comparing methods. For this reason, it is recommended to apply either direct rating or rank exploitation in future work in lieu of SRF.

\section{REFERENCES}

Baldwin, J.R. and Gorecki, P. (1998), The Dynamics of Industrial Competition: A North American Perspective, Cambridge University Press.

Barron, F.H. and Barrett, B.E. (1996), "Decision Quality Using Ranked Attribute Weights”, Management Science, Vol. 42 No. 11, pp. 1515-1523.

Benhayoun Sadafiyine, L., Le Dain, M.-A. and Dominguez-Péry, C. (2017a), "Designing a maturity grid to measure the knowledge absorptive capacity of a SME integrated in an innovation collaborative network", The 24th International Innovation and Product Development Management Conference, Reykjavik, Iceland, available at: https://hal.archives-ouvertes.fr/hal-01480035.

Benhayoun Sadafiyine, L., Dominguez-Péry, C. and Le Dain, M.-A. (2017b), "Towards an operationalization of knowledge absorptive capacity for a collaborative innovation network", European Academy of

Management Conference EURAM. 
Beynon, M. (2002), “An analysis of distributions of priority values from alternative comparison scales within AHP”, European Journal of Operational Research, Vol. 140 No. 1, pp. 104-117.

Blomqvist, K. and Levy, J. (2006), "Collaboration capability a focal concept in knowledge creation and collaborative innovation in networks", International Journal of Management Concepts and Philosophy, Vol. 2 No. 1, p. 31.

Chang, P.T. and Lee, E.S. (1995), "The estimation of normalized fuzzy weights", Computers and Mathematics with Applications, Vol. 29 No. 5, pp. 21-42.

Choo, E.U., Schoner, B. and Wedley, W.C. (1999), "Interpretation of criteria weights in multicriteria decision making”, Computers and Industrial Engineering, Vol. 37 No. 3, pp. 527-541.

Doyle, J.R., Green, R.H. and Bottomley, P.A. (1997), "Judging Relative Importance: Direct Rating and Point Allocation Are Not Equivalent”, Organizational Behavior and Human Decision Processes, Vol. 70 No. 1, pp. 65-72.

Dubois, D. and Prade, H. (1980), "Fuzzy Sets and Systems: Theory and Applications”, edited by Ames, W. Mathematics in Science and Engineering, Vol. 144, Academic Press, Inc.

Eckenrode, R. (2018), "Weighting Multiple Criteria”, Management Science, Vol. 12 No. 3, pp. 180-192.

Edwards, W. (1977), "How to Use Multiattribute Utility Measurement for Social Decisionmaking", in Bell, D.E., Keeney, R.L. and Raiffa, H. (Eds.), Conflicting Objectives in Decisions, John Wiley \& Sons, Bath, pp. 247-276.

Edwards, W. and Barron, F.H. (1994), "Smarts and smarter: Improved simple methods for multiattribute utility measurement”, Organizational Behavior and Human Decision Processes.

Figueira, J. and Roy, B. (2002), "Determining the weights of criteria in the ELECTRE type methods with a revised Simos' procedure”, European Journal of Operational Research, Vol. 139 No. 2, pp. 317-326.

Gendreau, E. (2017), A Multi-Criteria Multi-Actor Approach to Measure the Knowledge Absorptive Capacity within a Collaborative Innovation Network, Grenoble Insititut Polytechnique.

Gendreau, E. (2018), An Investigation into the Usability of an Innovation Management Assessment Tool, Clemson University.

Gendreau, E.J., O’Shields, S.T. and Summers, J.D. (2017), "Developing a Method for Classifying Design Enablers", IDETC/CIE, ASME, Cleveland, Ohio.

Hajkowicz, S.A., McDonald, G.T. and Smith, P.N. (2000), “An evaluation of multiple objective decision support weighting techniques in natural resource management", Journal of Environmental Planning and Management, Vol. 43 No. 4, pp. 505-518.

Ho, W., He, T., Lee, C.K.M. and Emrouznead, A. (n.d.), "Strategic logistics outsourcing: An integrated QFD and fuzzy AHP approach".

Honda, T., Yang, M.C., Dong, A. and Ji, H. (2010), "A comparison of formal methods for evaluating the language of preference in engineering design", Proceedings of the 2010 ASME IDETC International Design Engineering Technical Conferences \& Information in Engineering Conference, IDETC/CIE2010, Vol. 5, pp. 297-306.

Krug, S. (2010), Rocket Surgery Made Easy: The Do-It-Yourself Guide to Finding and Fixing Usability Problems, edited by Davis, N., New Riders, Berkeley, CA.

Malczewski, J. (1999), GIS and Multicriteria Decision Analysis, John Wiley \& Sons.

Mardani, A., Jusoh, A. and Zavadskas, E.K. (2015), "Fuzzy multiple criteria decision-making techniques and applications - Two decades review from 1994 to 2014”, Expert Systems with Applications, Elsevier Ltd, Vol. 42 No. 8, pp. 4126-4148.

Saaty, T.L. (2008), "Decision making with the analytic hierarchy process", International Journal of Services Sciences, Vol. 1 No. 1, p. 83.

San Cristóbal Mateo, J.R. (2012), Multi Criteria Analysis in the Renewable Energy Industry, available at: https://doi.org/10.1007/978-1-4471-2346-0_4.

Simos, J. (1990), Évaluer l'impact Sur l'environnement : Une Approache Originale Par l'analyse Multicritère et La Négociation, Presses polytechnique et universitaires romandes, Lausanne, Suisse.

Todorova, G. and Durisin, B. (2016), “Absorptive Capacity : Valuing a Reconceptualization”, Vol. 32 No. 3, pp. 774-786.

Triantaphyllou, E. (2000), "Multi-criteria decision making methods: a comparative study", p. 290.

Von Winterfeldt, D. and Edwards, W. (1993), "Decision analysis and behavioral research", Cambridge Univ. Press, Cambridge, MA (USA).

Zahra, S.A. and George, G. (2002), “Absorptive Capacity : A Review , Reconceptualization , and Extension”, The Academy of Management Review, Vol. 27 No. 2, pp. 185-203.

Zardari, N.H., Ahmed, K., Shirazi, S.M. and Yusop, Z.B. (2015), "Weighting Methods and Their Effects on Multi-Criteria Decision Making Model Outcomes in Water Resources Management.”, Book, available at: https://doi.org/10.1007/978-3-319-12586-2 ISSN.

Zhang, D., Yu, P.L. and Wang, P.Z. (1992), "State-dependent weights in multicriteria value functions", Journal of Optimization Theory and Applications, Vol. 74 No. 1, pp. 1-21. 